\title{
Effect of tool rotational speed on force generation, microstructure and mechanical properties of friction stir welded Al-Mg-Cr-Mn (AA 5052-O) alloy
}

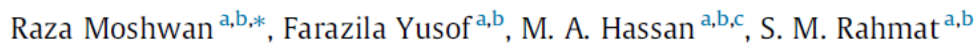

${ }^{a}$ Department of Mechanical Engineering, University of Malaya, 50603 Kuala Lumpur, Malaysia

${ }^{\mathrm{b}}$ Centre of Advanced Manufacturing and Material Processing (AMMP Centre), University of Malaya, 50603 Kuala Lumpur, Malaysia

${ }^{c}$ Department of Mechanical Engineering, Assiut University, 715116, Egypt

A R T I C L E I N F O

Article history:

Received 25 July 2014

Accepted 16 October 2014

Available online 24 October 2014

\section{Keywords:}

Friction stir welding

Tensile strength

Vickers hardness test

Intermetallic phase

\begin{abstract}
A B S T R A C T
Friction stir welding (FSW) between $3 \mathrm{~mm}$ thick AA 5052-0 aluminum alloy plates was investigated in the present study. Different welded specimens were produced by employing a constant tool traverse speed of $120 \mathrm{~mm} / \mathrm{min}$ and by varying rotating speeds from 800 to $3000 \mathrm{rpm}$. The welded joints were characterized by its appearances, microstructural and mechanical properties at room temperature. The measurement of different forces acted on the tool during the FSW of AA 5052-0 plates provided a significant insight to determine the quality of the welded joints. From the appearances of the welded joints it was evident that except the tool rotational speed of $3000 \mathrm{rpm}$ all other rotational speeds produced sound welded joints with smooth surface. The joint produced at $1000 \mathrm{rpm}$ yielded a maximum tensile strength of $132 \mathrm{MPa}$ which was $74 \%$ of the base material strength. Field emission scanning electron microscopy (FESEM) and energy dispersive spectroscopy (EDS) analyses on the stir zone suggested that, $\beta$ - $\mathrm{Mg}_{2} \mathrm{Al}_{3}$ intermetallic phases of the base material were mechanically fractured, smeared and mixed to different geometries due to tool stirring. The dissolution and redistribution of $\beta-\mathrm{Mg}_{2} \mathrm{Al}_{3}$ second phase particles in the stir zone had a considerable effect on the reduction of the tensile strength of the welded joints. The reduction in hardness at the nugget zone (NZ) of the welded joints under different tool rotational speeds could be attributed to the dislocation of Mg-rich phases and segregation of $\mathrm{Mg}$ solute atoms at grain boundaries, which drew solute Mg atoms away from the $\alpha$-aluminum matrix.
\end{abstract}

(c) 2014 Elsevier Ltd. All rights reserved.

\section{Introduction}

The requirements of aluminium and magnesium alloys as a light weight materials have been increasing in manufacturing industries to reduce the weight of product without sacrificing its structural strength [1]. Magnesium $(\mathrm{Mg})$ containing aluminium alloys are belonging to the 5-xxx series currently considered as potential aerospace and shipbuilding materials due to acceptable combination of room and high temperature properties. Obtaining sound welded joints of these alloys are still an appeal for many researchers. Friction stir welding (FSW) is an innovative solid-state joining technique which has been came up with The Welding Institute (TWI) in 1991 in an attempt to weld aluminium alloys [2] FSW process does not involve melting and recasting of the base

* Corresponding author at: Department of Mechanical Engineering, University of Malaya, 50603 Kuala Lumpur, Malaysia. Tel.: +603 79677633; fax: +603 79675330 . E-mail addresses: raza_moshwan@siswa.um.edu.my, raza_moshwan2007@ yahoo.com (R. Moshwan).

http://dx.doi.org/10.1016/j.matdes.2014.10.043

0261-3069/○ 2014 Elsevier Ltd. All rights reserved. materials [3] that are joined during the process. In addition, these welded joints are possessed higher strength to weight ratio and finer microstructure compare to conventional welding.

Friction stir welding (FSW) is emerged as a promising solidstate joining process with the potential to join low melting point materials, particularly aluminium alloys [4]. The most attractive reasons for joining aluminium alloys through this process are the avoidance of solidification defects formed by conventional fusion welding process, low distortion and residual stresses. Consequently, FSW is effective and has been systematically developed for joining aluminium alloys, especially those usually are considered non-weldable or difficult to weld such as $2 \mathrm{xxx}, 5 \mathrm{xxx}$ and $7 \mathrm{xxx}$ series alloys. The basic principle of FSW is associated with the plunging a rotating tool into the workpiece that is intended for welding. The rotating tool pin slowly penetrates the work piece, until the tool shoulder touches the top surface of the workpieces and it is held there while the material is being softened with generated frictional heat. Subsequently, the tool traverses along the 
path of interest, thus inducing the welding of the plasticized volume behind it. Since the melting of the materials is avoidable, FSW checks problems such as distortion and metallurgical reactions which are typically appeared in conventional fusion welding processes.

In friction stir welding of aluminum alloys, a considerable change is occurred in microstructure in different area that could be easily obtained by the severe strain rates and thermal cycles $[5,6]$. The base material is usually composed of elongated grain structure, which is turned into a fine grain refinement due to the severe plastic deformation aided by the tool at the joint interface. The nugget zone (NZ) which is normally thought to be the tool shape mostly depends on the interaction between workpiece and tool pin and shoulder and process parameters. Fujii et al. [7], in their research reported a detail discussion on the nugget formation and its size and shape along with the effect of the tool geometry on its while the detail of different regions in the friction stir welded joint was reported by Threadgill et al. [8].

All commercial wrought and cast alloys contain some insoluble particles in the aluminum matrix. In unalloyed aluminum (1 xxx series), the particles consist of phases that contain impurity elements, mainly iron and silicon. In 3xxx series alloys, primary and eutectic particles of intermetallic phases of manganese with aluminum, silicon and iron may be present. Alloys of the $5 x x x$ series contain particles of $\mathrm{Mg}_{2} \mathrm{Al}_{3}, \mathrm{Mg}_{2} \mathrm{Si}$ and intermetallic phases with chromium and manganese. Heat-treatable wrought and cast alloys contain soluble phases, which appear in various amounts and at various locations in the microstructure, depending on the thermal history of the specimen. In $2 x x x$ series wrought alloys, the soluble phase is $\mathrm{CuAl}_{2}$ or CuMgAl 2 . In $6 \mathrm{xxx}$ series alloys, the most common intermetallic phase is $\mathrm{Mg}_{2} \mathrm{Si}$; particles of excess silicon may also be present. In $7 \mathrm{xxx}$ series alloys, $\mathrm{MgZn}_{2}$ is the principle soluble phase but others may also be present. The precipitate formed in these alloys is usually extremely fine.

Nowadays, research is still in progress on FSW of aluminum $5 x x x$ series. Currently, aluminum alloys are used as alternative to steel in many applications because of their light weight, good weldability, good formability, good strength and corrosion resistance. AA 5xxx aluminum alloys, including AA 5052, AA 5754 and AA 5083 have been widely used in automotive and marine industries. The growing applications have been adjed chalienges for improvement of the welding processes. Among the AA $5 x x x$ series of aluminum alloys, the FSW of AA 5083 is the most studied, either in similar [9-12] and dissimilar [13,14] welding combinations. Peel et al. [9] studied microstructure, mechanical properties and residual stresses as a function of welding speed in aluminium AA5083 friction stir welds. Lombard et al. [11] reported effect of process parameters on the residual stresses in AA5083-H321 friction stir welds. Kimapong and Watanabe [13] studied dissimilar friction stir lap joint between A5083 aluminum alloy and SS400 steel. Some efforts were also put to study the FSW of the AA 5754 [15], AA 5456 [16,17], AA 5251 $[18,19], A A 5182$ [20], AA 5052 [21] and AA 5086 [22,23] series of alloys. Some of these Authors analyzed the influence of the rotating speed [15] the advancing speed $[9,23]$ both of these factors together [10-12] and even the interaction of tool's geometry with these parameters $[9,12,15]$ on weld quality.

All in all, the above mentioned researches only yielded preliminary and limited results of the mechanical and microstructural properties of the welded joints. However, the intermetallic phases of the base materials and the subsequent effect of these phases on the joint quality were not analyzed for the current material $A A$ 5052-0 alloy. Therefore, it is necessary to further reveal the effect of process parameters as well as the effect of dissolution of second phase particles on the microstructure and mechanical properties of the friction stir welded AA 5052-O plates. Thus, the present work is aimed to the evaluation of the tool rotational speed effect on tool force generation, mechanical and microstructural behavior of $3 \mathrm{~mm}$ thick friction stir welded AA 5052-O alloy plates.

\section{Experimental procedure}

A conventional computer numerical control (CNC) high speed milling machine (MITSUI SEIKI model VT3A) was used for FSW process. The assembly of jig and fixture with rotating tool during the welding process is shown in Fig. 1. The size of the parent metal was $100 \mathrm{~mm} \times 50 \mathrm{~mm} \times 3 \mathrm{~mm}$. The chemical composition and physical properties of AA 5052 are listed in Tables 1 and 2 respectively. A tool made of hardened mild steel was used to produce the welding joints (Fig. 2). The shoulder and probe diameter of the tool were $8 \mathrm{~mm}$ and $4.5 \mathrm{~mm}$ respectively. Five different tool rotational speeds $800,1000,1500,2000$, and $3000 \mathrm{rpm}$ were used while the traverse speed was remained constant at $120 \mathrm{~mm} / \mathrm{min}$.

Standard metallographic techniques were used to analyze the resultant joined specimens. Cross-sections of the welded joints were progressively grinded using different grades of emery paper and finally polished using diamond compounds $(6,3$ and $1 \mu \mathrm{m})$ and $0.3 \mu \mathrm{m}$ alumina. The specimens were etched with modified Keller reagent ( $12.5 \mathrm{ml} \mathrm{HNO}, 7.5 \mathrm{ml} \mathrm{HCl}, 5 \mathrm{ml} \mathrm{HF}$ in $25 \mathrm{ml}$ distilled water). The microstructure of the specimen was evaluated by an optical microscope (model: Olympus), scanning electron microscope (SEM- Model: Quanta 2000) and field emission scanning electron microscopy (FESEM). Elemental characterization was conducted by employing energy dispersive spectroscopy (EDS). Mechanical tests of the specimens were included tensile tests and hardness measurements. ASTM: E8 sub size standard was followed for the tensile test specimen. The tensile tests were carried out by INSTRON Universal Testing Machine (model 3369). The direction of the tensile test specimens was transverse to the welding direction. The hardness in the welded area was measured by a Vickers micro-indentation (Shimadzu, HMV 2T E) using $0.98 \mathrm{~N}$ load with 5 s holding time.

In order to measure the tool force during the welding process (Fig. 3) the machine was instrumented with a Kistler three-axis piezoelectric dynamometer (type 9255B). National instrument (NI) 9205 data acquisition (DAQ) device was used to scan the data. A customize Labview program was developed to get force from generated voltage.

\section{Results and discussion}

\subsection{Appearances of the welded joints}

Macroscopic images were taken to investigate the surface appearances of the welded joints. The effect of tool rotational speeds on surface appearances of the welded joints is shown in Fig. 4. The tool was traveled at $120 \mathrm{~mm} / \mathrm{min}$ at a constant

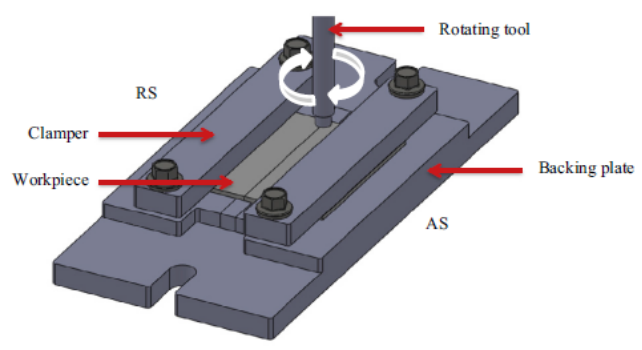

Fig. 1. Assembly of jig and fixture with rotating tool. 
Table 1

Chemical composition of AA 5052-0 in mass \%

\begin{tabular}{lllllllll}
\hline & $\mathrm{Al}$ & $\mathrm{Si}$ & $\mathrm{Fe}$ & $\mathrm{Cu}$ & $\mathrm{Mn}$ & $\mathrm{Mg}$ & $\mathrm{Cr}$ & Other \\
\hline AA 5052 & Bal. & $<0.25$ & $<0.4$ & $<0.1$ & $0.15-0.35$ & $2.2-2.8$ & $<0.1$ & $<0.15$
\end{tabular}

$0.2 \mathrm{~mm}$ depth of shoulder penetration. The pin was plunged into the workpieces through the centerline of the welding direction. It pressed the base material downward, fill up the gap between two plates and thus welding joint was obtained. Defect free welded joints were successfully obtained at tool rotational speeds of 800 , 1000,1500 and $2000 \mathrm{rpm}$ as can be seen in Fig. 4a-d. Previously defect free welded joints were obtained for different aluminum alloys at rotational speeds of $900-1300 \mathrm{rpm}$ by Balasubramanian et al. [24]. It can be noted that, semicircular traces were quite discernable at all rotational speeds while the surface morphology became smoother as the tool rotational speed increased. However, at $3000 \mathrm{rpm}$ a continuous channel-like void was formed in the advancing side near the NZ/TMAZ interfaces and extended along the welding direction. It is well reported that, for a constant traverse speed if the tool rotational speed is high an excess heat input takes place. This excess heat increases the fluidity of metal and makes turbulence flow in the welded zone which is resulted in the possibility of the formation of cavities [25]. Thus we can assume that, there might have optimum rotational and traverse speeds combinations for obtaining defect free welds with smooth surface for the friction stir welding of AA 5052-O plates.

\subsection{Characterization of microstructure}

A typical transverse section of FSW joint perpendicular to welding line at a tool rotational speed of $800 \mathrm{rpm}$ is shown in Fig. 5. The weld was bounded on either side by unaltered base material (BM). Although BM near the weld zone experienced elevated temperature during welding, this material exhibited the same properties as the workpiece was in the as-received condition. Closer to the weld called heat-affected zone (HAZ), which was heated sufficiently during welding to alter its properties without plastic deformation of the original grain structure. The alteration of properties in the HAZ might be included changes in the strength, ductility, corrosion susceptibility and toughness of the workpiece but typically not changes in grain size or chemical makeup. Heating in the HAZ was generally high enough in base material to result in recovery of cold work and coarsening of precipitates which was the root cause of changes in properties in this region. The thermomechanically affected zone (TMAZ) was encompassed by all of the plastically deformed material within the joint region. In this region, the workpiece was sufficiently heated and softened and the process forces were sufficiently high to result in plastic deformation of the original grain structure. Next to the TMAZ there was recrystallized zone which is so called nugget zone (NZ). Further, in aluminum alloys the nugget material is generally composed of fine grain size material and is considered to have experienced severe plastic deformation due to interaction with the welding tool pin and in some cases may actually mimic the shape of the pin profile.
However, in workpiece that experienced thermally induced phase transformation, the TMAZ may consisted entirely of recrystallized material, while in other materials the TMAZ may be completely unrecrystallized, without regarding to the size or shape of the pin.

It is noteworthy to mention that, both sides of the nugget zone were comprised of a new interface by the newly composed nugget zone and base material. These interfaces were differentiated by the relative directions of tool rotation and tool advancement. The interface for which direction of tool rotation and advancement were parallel is known as advancing side (AS). On the other hand, the interface for which direction of tool rotation and traverse were opposite is known as 'retreating side' (RS).

The microstructure of the base material and the weld nugget zone at different tool rotational speeds is shown in Fig. 6. It could be seen, for all tool rotational speeds the weld nuggets were invariably showed fine recrystallized equiaxed grains because of severe plastic deformation and high temperature that was sufficient to cause dynamic recrystallization by rotation and traversing of FSW tool during welding. During the friction stir welding the nugget zone was composed of newly equiaxed grain which was the outcome of breaking up the original microstructure due to the severe plastic deformation and frictional heat input. This was resulted in many microstructural modification included coarse precipitation, dynamic recrystallization and microtexture transformation. This phenomenon is described in next section through FESEM analysis.

To investigate the morphology of the stir zone FESEM analysis was performed. Fig. 7 shows the FESEM images of the nugget zone of welded joints at all rotational speeds and base material. Fig. 7a, b, c, d, e, f are representing the FESEM images of base material, $800 \mathrm{rpm}, 1000 \mathrm{rpm}, 1500 \mathrm{rpm}, 2000 \mathrm{rpm}$ and $3000 \mathrm{rpm}$ respectively. From Fig. 7a, in the base material the particles of $\mathrm{Mg}_{2} \mathrm{Al}_{3}$ could be easily identified as denoted by arrow sign in the $\alpha(\mathrm{Al})$ aluminum matrix. However, from Fig. 7b-f at all rotational speed $\mathrm{Mg}_{2} \mathrm{Al}_{3}$ particles and aluminum dendrite were significantly broken up and subsequently a heterogenous distribution of smaller $\mathrm{Mg}_{2} \mathrm{Al}_{3}$ particles was created in $\alpha(\mathrm{Al})$ matrix. The high magnification FESEM images at all the rotational speeds revealed suspended particles with different shape covered on the surface of the aluminum matrix which was the resultant of redistribution of several particles within the stir zone. Thus it is believed that, these insoluble particles have a great contribution to reduce the hardness of the stir zone which is described later on.

Moreover, it could be seen at all the rotational speed a considerable amount of coarse despersoids are randomly distributed in the $\alpha(\mathrm{Al})$ matrix. As identified by the EDS analysis in Fig. 8, such coarse dispersoids were consisted of aluminum, chromium, magnesium, manganese, iron, zinc and silicon elements and it is believed that they have a considerable negative effect on strengthening of the welded joints. However, particles in the aluminum matrix in Fig. 7 showed the evidence of the existence of $\mathrm{Mg}_{2} \mathrm{Al}_{3}$, $\mathrm{Mg}_{2} \mathrm{Si}$ and intermetallic phases with chromium and manganese which is directly supported the findings of EDS analysis in Fig. 8. All this phases of the base material were mechanically fractured smeared and mixed to different geometries due to tool stirring. The dissolution and redistribution of $\beta-\mathrm{Mg}_{2} \mathrm{Al}_{3}$ second phase

Table 2

Physical properties of base material.

\begin{tabular}{|c|c|c|c|c|c|c|}
\hline \multirow[b]{2}{*}{ Material } & \multicolumn{5}{|c|}{ Mechanical properties at room temperature } & \multirow{2}{*}{$\begin{array}{l}\text { Thermal } \\
\text { properties } \\
\text { Melting point }\left({ }^{\circ} \mathrm{C}\right)\end{array}$} \\
\hline & $\begin{array}{l}\text { Yield strength } \\
(\mathrm{MPa})\end{array}$ & $\begin{array}{l}\text { Ultimate tensile strength } \\
\text { (MPa) }\end{array}$ & $\begin{array}{l}\text { Modulus of elasticity } \\
(\mathrm{GPa})\end{array}$ & $\begin{array}{l}\text { Elongation at yield } \\
\text { (\%) }\end{array}$ & $\begin{array}{l}\text { Elongation at break } \\
(\%)\end{array}$ & \\
\hline AA 5052 & 89.6 & 193 & 70.3 & - & 25 & $607-649$ \\
\hline
\end{tabular}




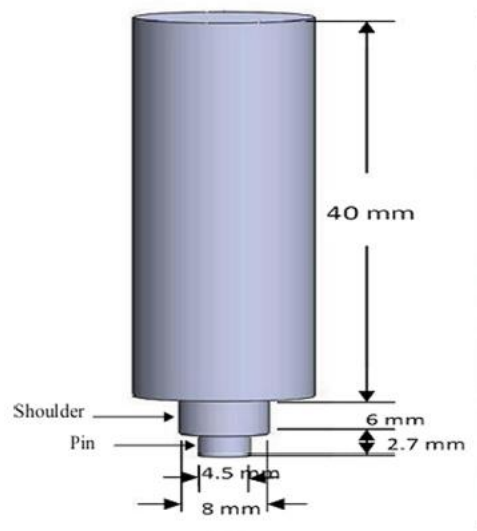

(a)

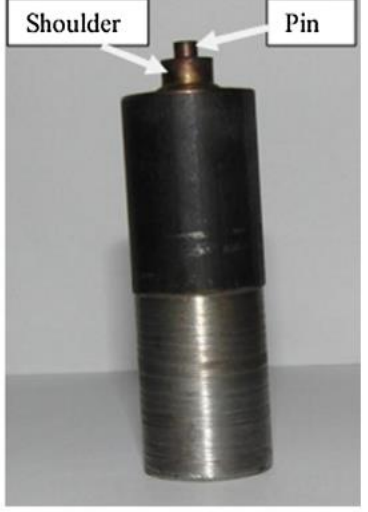

(b)

Fig. 2. (a) Schematic diagram of tool. (b) Rotating tool consists of shoulder and pin.

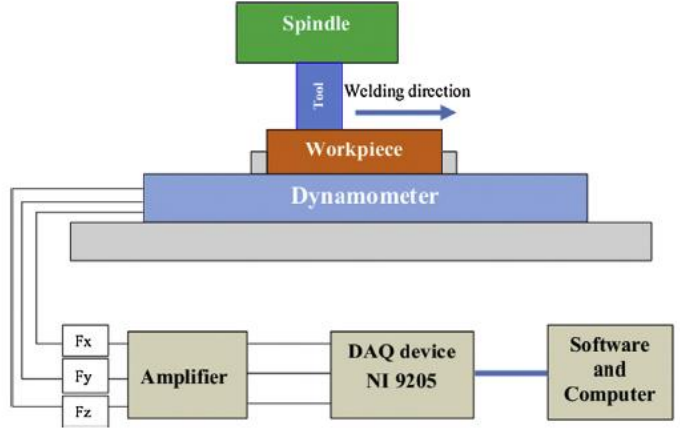

Fig. 3. Schematic diagram for tool force measurement during friction stir welding of AA 5052-0 plates.

particles in the stir zone had a considerable effect in the reduction of the tensile strength of the welded joints which is described in the next chapter elaborately.

It is important to keep in mind that, there was a significant thermodynamic effect on the $\beta-\mathrm{Mg}_{2} \mathrm{Al}_{3}$ intermetallic phase due to induced thermal energy as a result of the mechanical energy input. The heating and excessive deformation due to tool rotation during friction stir welding process was resulted in diffusion of magnesium from the grain interiors to the grain boundaries to form more $\beta$-phase $\left(\mathrm{Mg}_{2} \mathrm{Al}_{3}\right)$ particles either in continuous or discontinuous manner. The mechanical energy input caused an enhancement of the thermodynamic driving force and the kinetics of mass transport. The total activation energy that is responsible for the formation of new intermetallic compound ( $\left.E_{\mathrm{IMC}}\right)$ can be defined as

$E_{\mathrm{IMC}}=E_{\mathrm{Sat}}+E_{\mathrm{Eff}}$

where $E_{\text {Sat }}$ is the activation energy for the formation of supersaturated solid solution during the time before the intermetallic compound appears at the joining interface and $E_{\mathrm{Eff}}$ is the activation energy for the subsequent transformation of supersaturated solid solution into intermetallic compound.
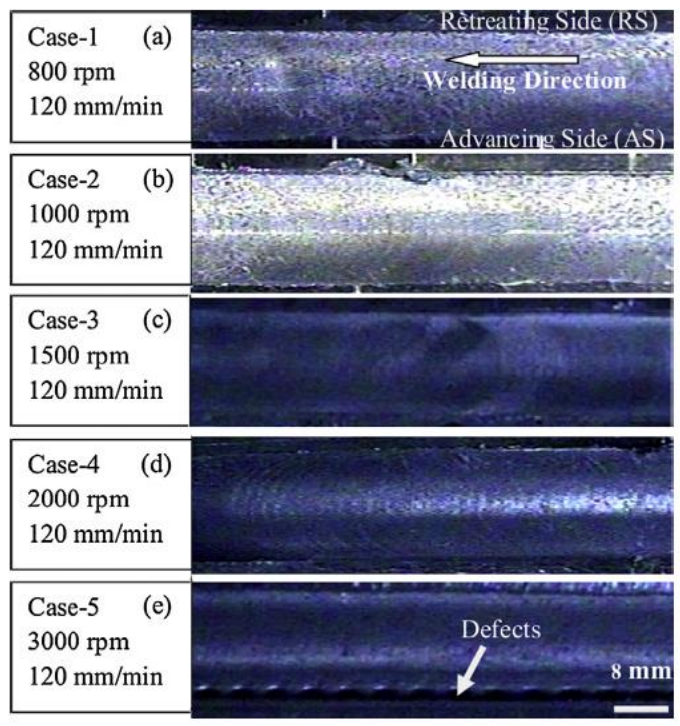

Fig. 4. Appearance of the welded joint at constant traverse speed of $120 \mathrm{~mm} / \mathrm{min}$ with tool rotational speed of (a) $800 \mathrm{rpm}$, (b) $1000 \mathrm{rpm}$, (c) $1500 \mathrm{rpm}$, (d) $2000 \mathrm{rpm}$ and (e) $3000 \mathrm{rpm}$.

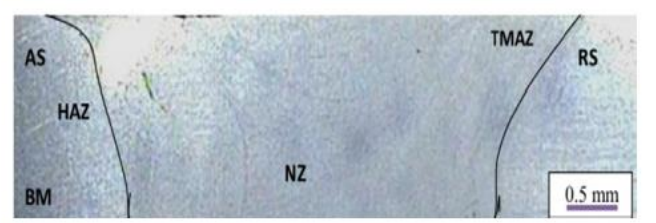

Fig. 5. Cross sectional micrograph for a specimen welded at tool rotational speed of $800 \mathrm{rpm}$. 

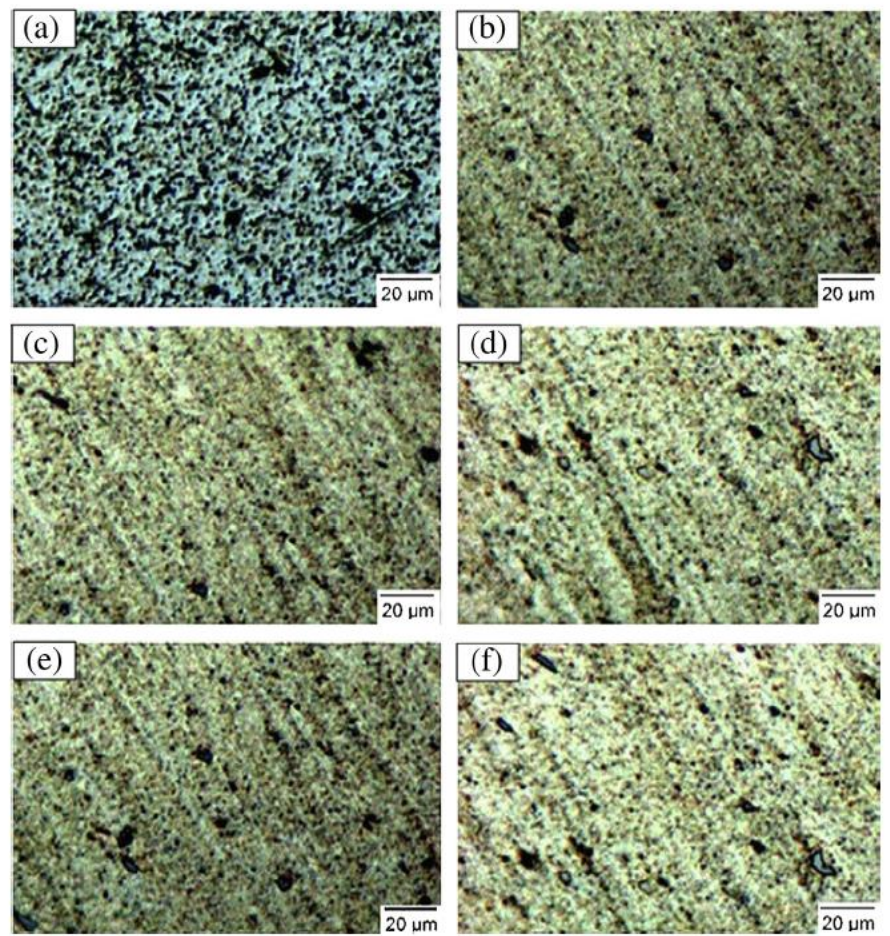

Fig. 6. Microstructure of the base material and weld nugget zone: (a) base material, (b) $800 \mathrm{rpm}$, (c) $1000 \mathrm{rpm}$, (d) $1500 \mathrm{rpm}$, (e) $2000 \mathrm{rpm}$ and (f) $3000 \mathrm{rpm}$.

The rate of transforming the supersaturated solid solution into intermetallic compound $\left(\bar{N}_{\text {Eff }}\right)$ can be expressed by the Arrhenius equation as follows

$\bar{N}_{\text {Eff }}=K_{\text {Eff }} \exp \left[-E_{\text {Eff }} / \mathrm{RT}\right]$

where $K_{\mathrm{Eff}}$ is the rate constant for converting supersaturated solid solution into intermetallic compound. $R$ is gas constant and $T$ is temperature of diffusion in Kelvin. The effective activation energy $E_{\mathrm{Eff}}$, depends on the factors involved in this transformation

$E_{\mathrm{Eff}}=n W+E_{\mathrm{cr}}+n e$

where $n W$ is the activation energy essential for localized fluctuation in composition. $E_{\mathrm{cr}}$ is the activation energy involved in restricting of the crystal lattice when the intermetallic phases were formed and $n e$ is the deformation energy of the matrix surrounding the nucleus.

However, it can be noted that, the degree of corrosion resistivity of the aluminum alloy is highly influenced by the intermetallic phases which indirectly refer to thermodynamic effect. The continuity of aluminum oxide film that protects the aluminum surface from the corrosion is strongly affected by the microstructure of the metal in particular by the presence and volume fraction of intermetallic phases. Corrosion resistance is affected by this factor and by the solution potential relationship between intermetallic compounds and the solid solution matrix in which they occur. In most environments, resistance to corrosion of unalloyed aluminum is increased with the increase of purity. In this particular research, since thermodynamic effect from the induced heat energy and severe plastic deformation of the material mixing during the process resulted in increasing in intermetallic phases thus we can infe that thermodynamic effect had a great contribution to deteriorate the corrosion resistivity of the friction stir welded AA 5052-O joints.

\subsection{Tensile strength analysis}

The maximum tensile load was selected from the stress-strain diagram in every experiment in order to indicate the variation of the weld strength. The engineering stress strain diagram for the base material and the friction stir welded joints are shown in Figs. 9 and 10 respectively. As can be seen from Figs. 9 and 10, all the tool rotational speeds produced lower yield strength and ultimate tensile strength compare to base material strength. The tensile strength was increased to a maximum value as the tool rotational speed increased from $800 \mathrm{rpm}$ to $1000 \mathrm{rpm}$. Further increasing in rotational speed above $1000 \mathrm{rpm}$ caused gradual reduction in tensile strength. This trend was quite discernable in all the joints from $1500 \mathrm{rpm}$ to $3000 \mathrm{rpm}$. For a fixed tool traverse speed the ultimate tensile strength of the welded joint was maximum at $1000 \mathrm{rpm}$ while the minimum at $3000 \mathrm{rpm}$. The ultimate tensile strength of the welded joint at $1000 \mathrm{rpm}$ was about $132 \mathrm{MPa}$ which was $26 \%$ lower than the base material strength. The ultimate tensile strength of the welded joints corresponding to $800 \mathrm{rpm}, 1500 \mathrm{rpm}, 2000 \mathrm{rpm}$ and $3000 \mathrm{rpm}$ were $112 \mathrm{MPa}, 108 \mathrm{MPa}, 99 \mathrm{MPa}$ and $68 \mathrm{MPa}$ respectively.

Fig. 11 depicts the effect of tool rotational speed on tensile behavior of friction stir welded AA 5052 joints. It is well reported that, tensile strength of the friction stir welded joints are highly influenced by tool rotational speed [26]. As the tool rotational speed increased the tensile strength is also increased, reached to a maximum value and then gradually decreased with further 

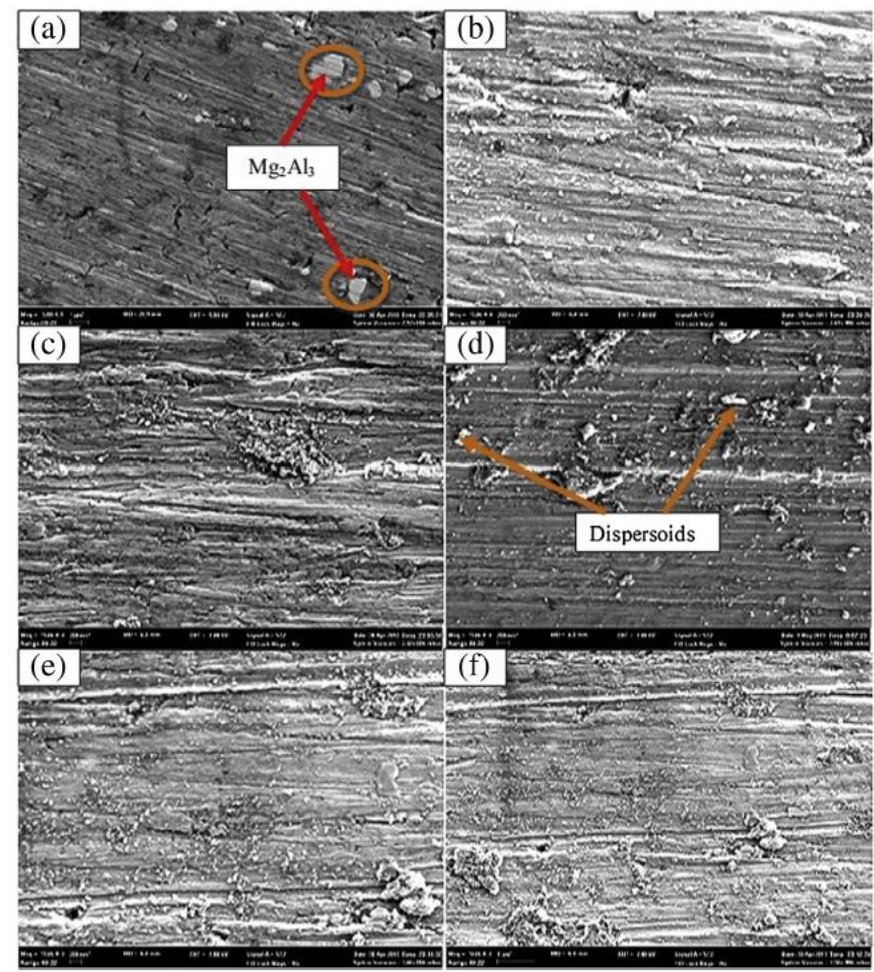

Fig. 7. FESEM images of the base material and the weld nugget zone at different tool rotational speed (a) base material, (b) $800 \mathrm{rpm}$, (c) $1000 \mathrm{rpm}$, (d) $1500 \mathrm{rpm}$, (e) $2000 \mathrm{rpm}$ and (f) $3000 \mathrm{rpm}$.

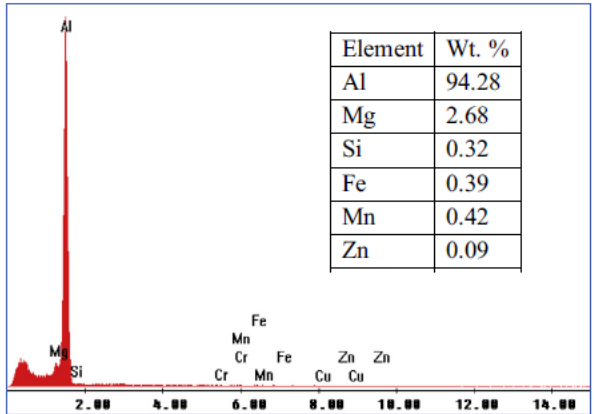

Fig. 8. A representative EDS analysis on the stir zone of the friction stir welded AA 5052 plates at a tool rotational speed of $1000 \mathrm{rpm}$.

increasing in rotational speed. In this research, both ultimate tensile strength (UTS) and yield strength of the welded joints were initially increased with the increase in tool rotational speed from $800 \mathrm{rpm}$ to $1000 \mathrm{rpm}$, and reached its maximum value at $1000 \mathrm{rpm}$ then decreased with further increasing in tool rotational speed. Tool rotational speed was responsible for stirring and mixing of plasticized material around the rotating tool pin which in turn increased the temperature of the plasticized material. When the tool rotational speed was above $1000 \mathrm{rpm}$ higher heat was

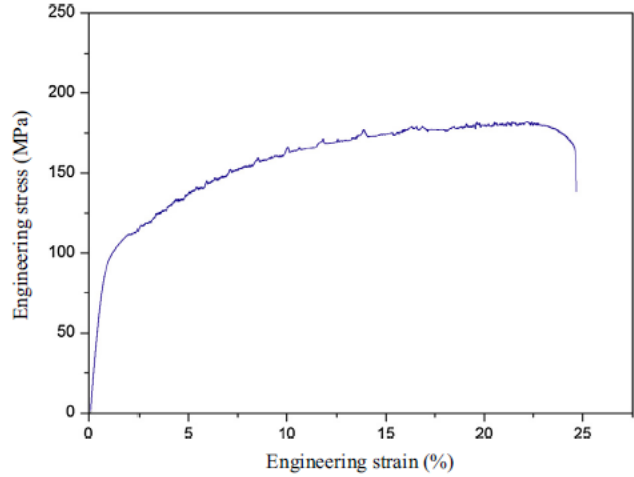

Fig. 9. Engineering stress strain diagram for base material.

generated in the stir zone due to increasing in relative velocity between rotating tool and the substrate. Higher heat input resulted in increasing of grain growth and dissolution of second phase $\beta-\mathrm{Mg}_{2} \mathrm{Al}_{3}$ particles at weld zone. Similar study was reported by Elangovan et al. [27] in case of friction stir welding of AA 6061 aluminum alloy where they found the dissolution of $\mathrm{Mg}_{2} \mathrm{Si}$ particles that contributed to reduction in the bonding strength of the welded joints at the higher tool rotational speed. In addition, 


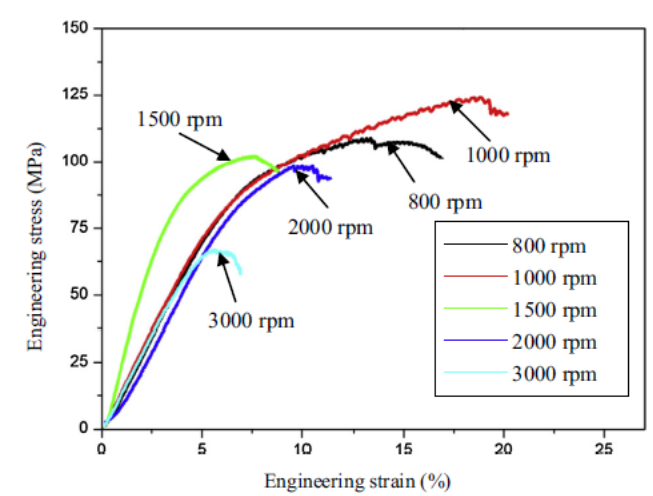

Fig. 10. Engineering stress strain diagram for friction stir welded joints of AA 5052 plates at different tool rotational speed.

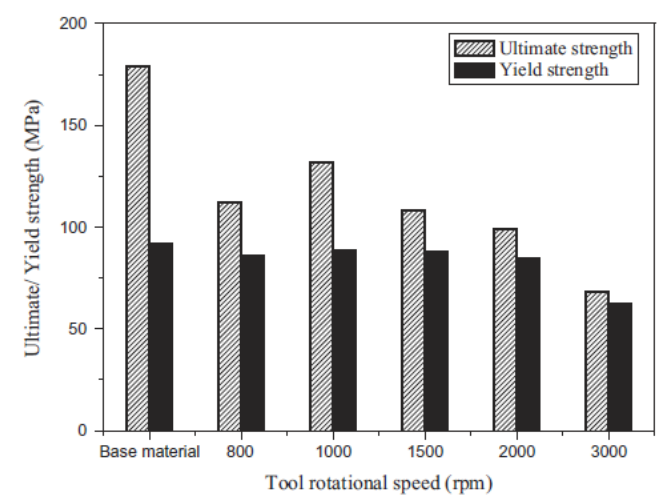

Fig. 11. Effect of tool rotational speed on tensile strength of the friction stir welded joint.

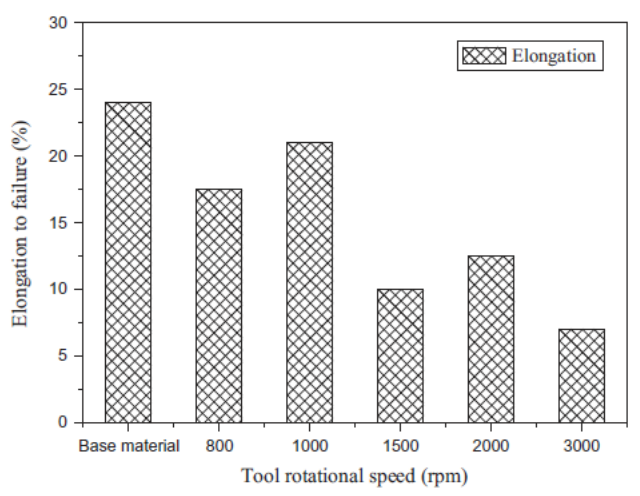

Fig. 12. Elongation to failure as a function of tool rotational speed. higher heat did not promote the nucleation of grains and precipitation of constituents of aluminum alloy [28]. When the tool rotational speed increased beyond $2000 \mathrm{rpm}$ an excess heat was generated at the weld zone that increased the turbulence of strained plasticized materials and formation of macro level defects at the weld zone. All these factors lead to poor joints with inferior tensile strength.

At lower tool rotational speed below $1000 \mathrm{rpm}$, heat generation at the weld zone was inadequate to strain the plasticized material that resulted in poor consolidation of material which ultimately degraded the tensile strength of the welded joints. Hence optimum tool rotational speed was essential to generate adequate frictional heat as it produced defect free welded joints by sufficient straining of plasticized material with fine recrystallized grains [29]. Higher tool rotational speed influenced the straining rate of the plasticized material caused change in grain size and precipitation in the weld zone. Another important reason of the decreasing in tensile strength from $1500 \mathrm{rpm}$ to $3000 \mathrm{rpm}$ was due to the turbulence of softened metal at higher rotational speeds in which the broken second phase particles $\beta-\mathrm{Mg}_{2} \mathrm{Al}_{3}$ and intermetallic compound were clustered to be coarse and segregated ones and non homogeneous distribution in the aluminum matrix [30].

The improvement of the friction stir welded joint strength is increased with the increasing in heat input per unit weld length up to a certain level. The increasing in rotational speed at a constant traverse speed results in increasing heat input monotonically that ultimately contribute to increasing the strength of the welded joint. As reported by Tang et al. [31] during the friction stir welding of AA 6061-T6, at constant traverse speed of $120 \mathrm{~mm} / \mathrm{min}$, an increase in rotary speed from 300 to $600 \mathrm{rpm}$ caused increase in peak temperature by $\sim 40{ }^{\circ} \mathrm{C}$ at the weld zone. Further high heat input accelerated the homogeneous distribution of second phase strengthening precipitates $\mathrm{MgZn}_{2}$ that resulted in reducing pores in the weld nugget zone and ultimately enhance the tensile strength of the welded joints. A similar results also reported by Hassan et al. [32] using rotational speed from 195 to $660 \mathrm{rpm}$ in case of friction stir welding of AA 7010 alloy. They found that, the ultimate tensile strength and \% elongation showed poor performance at lower rotational speed; as the rotational speed increased both tensile strength and \% elongation of welded joints improved considerably. The higher heat input allow the increasing of solute concentration and number of new fine grains in the weld zone that leads to improve in tensile behavior owing to a contraction in the density of second phase particles $\left(\mathrm{MgZn}_{2}\right)$. An investigation on microstructural phenomenon occurring in friction stir welding of aluminum alloy has been led by Barcellona et al. [33]. They have reported that the average value of the ultimate tensile strength of the friction stir welded AA 7075-T6 alloy plates was reduced to about $75 \%$ of the ultimate tensile strength of the base material owing to material softening from coarsening of fine precipitates. All these reports strongly support our present study where the ultimate tensile strength was considerably reduced when the rotational speed increased from $1000 \mathrm{rpm}$ to $3000 \mathrm{rpm}$ due to the coarsening and inhomogeneous distribution of second phase particles $\left(\mathrm{Al}_{2} \mathrm{Mg}_{3}\right)$ in the $\alpha(\mathrm{Al})$ matrix.

\subsection{Elongation}

The effect of tool rotational speed on elongation of the friction stir welded AA 5052 plates is shown in Fig. 12. The friction stir welded plates showed lower elongation than the parent material (about 24\%) in all cases. The \% elongation was increased as the tool rotational increased from $800 \mathrm{rpm}$ to $1000 \mathrm{rpm}$. Further increase in rotational speed from $1000 \mathrm{rpm}$ to 3000 caused the decreasing of \% elongation inconsistently. A maximum elongation value was found at $1000 \mathrm{rpm}$ while the tensile strength was also maximum. At

\section{Link to Full-Text Articles :}

http://www.sciencedirect.com/science/article/pii/S0261306914008310

\section{http://repository.um.edu.my/94959/1/FSW.pdf}

